\title{
Influence of mechanical deflector assisted electroless nickel deposits for wear resistance
}

\author{
J.T. Winowlin Jappes*, N.C. Brintha** and M. Adam Khan**** \\ * School of Automotive and Mechanical Engineering (SAME) and Centre for Surface Engineering, Kalasalingam Academy of Research and \\ Education (KARE), Krishnankoil, Tamilnadu, India \\ ** Department of Computer Science and Engineering and Centre for Surface Engineering, Kalasalingam Academy of Research and \\ Education, Krishnankoil, Tamilnadu, India \\ *.***Corresponding Author: adamkhanm@gmail.com
}

Submitted :06/08/2020

Revised : 22/08/2021

Accepted :05/09/2021

\begin{abstract}
This investigation reports the effect of mechanical deflector during coating on the mechanical properties of the Electroless Ni-P deposits. Micro hardness of the electroless Ni-P deposits was measured using Shimadzu micro hardness measuring unit employing a diamond indenter, and pin-on-disc wear tester was used to measure the wear resistance of the deposits. The characteristics of deposits produced in presence of mechanical deflector are found to be superior from those produced using conventional deposition techniques. Enhancement in properties correlated with modified crystallinity and the conversion of Ni-P into possible phosphides in the presence of mechanical deflector. It has been noticed that the coating efficiency has $30 \%$ hike with mechanical deflector. Annealing at $350^{\circ} \mathrm{C}$ has reached the maximum hardness of $950 \mathrm{Hv}$ and subsequent increase in wear resistance.
\end{abstract}

Keywords: Electroless deposition; Ni-P coating; Wear; Mechanical deflector; Incorporation.

\section{INTRODUCTION}

Electroless (autocatalytic) plating involves the presence of a chemical reducing agent in solution to reduce metallic ions to the metal state. By the controlled chemical reduction reaction, electroless coating chemistry has emerged as one of the leading growth areas in surface engineering, metal finishing, etc. The useful service life of electroless nickel plating baths is quite short. Consequently, nickel recovery from the plating bath is often not total or complete. The limited life span of the electroless nickel process makes the operational chemical costs and spent bath disposal costs significantly higher. Few researchers have proposed to modify the coating process to acquire the required properties. Researches have widely suggested the use of electrodialysis as a viable alternative to the traditional dump and remaking of electroless nickel solutions [1]. The electrodialysis unit is a series of alternating membranes with an applied electrical charge. The spent electroless nickel solution is circulated through one set of alternating membranes, while a second conductive solution $(5.0 \mathrm{~g} / \mathrm{L}$ sodium sulfate $)$ is circulated between the membranes containing the electroless nickel. The circulation of solutions and the application of current create flow of anions and cations. The process removes material from the electroless nickel solution and places it in the conductive solution. The membranes are designed to allow the passage of particles in only one direction. The spent solution, a cocktail of orthophosphite, hypophosphite, nickel, and chelators, would be normally considered as waste. 
The rate of removal is dependent upon the concentration and mobility of the ions in the electric field [2]. It has been suggested that the usage of nickel hypophosphite as a substitute for nickel sulfate and sodium hypophosphite has distinct benefits in life of the electroless nickel solutions [3,4].

This investigation proposed a mechanical deflector to attract the nickel ions produced as a result of autocatalytic reaction. The as-plated hardness of most electroless nickel coatings is approximately $600 \mathrm{VHN}$. It is evident that incorporation of phosphorous as alloying element in the nickel lattice affects the structure and properties of the asdeposited Ni-P coating [5]. In the as-deposited condition, most alloys usually contain some amount of amorphous material. As discussed in the preceding section, during heat treatment as the alloy is subjected to higher temperatures, a series of metastable precipitates are formed culminating ultimately in the formation of stable nickel phosphide (Ni3P) and crystalline nickel. In the process, the hardness of the alloy reaches a maximum and then decreases in a manner typical of precipitation hardening processes. The amount of nickel phosphide formed depends on the phosphorous content of the alloy and the time-temperature history of heat treatment $[6,7]$. The phosphorous content of deposits may range from 1 to 13 percent, and their structure may vary from pure crystalline beta phase to totally amorphous gamma phase. Their relative proportions have a marked influence on many of the properties of the coatings [6]. The degree of hardening that could be expected from EN deposits on aging at a given temperature depends on the phosphorus content and the aging time employed $[8,9]$.

The hardness of the coating heat treated up to $2000 \mathrm{C}$ is similar to that in the as-deposited specimen since at such relatively lower temperatures, no significant change in structure is expected. However, on increasing the treatment temperature to around 3300C (annealing for about $2 \mathrm{hrs)}$ ), a significant increase in hardness was observed followed through reduction in the hardness, while a further increase was observed in the treatment temperature to higher values. The reason for this reduction was attributed to crystal growth that achieved a maximum surface hardness of $916 \mathrm{HK}$ $(100 \mathrm{~g})(0.63 \mathrm{GPa})$ after $1 \mathrm{hr}$ at $4000 \mathrm{C}$. Martin [10] suggested the addition of nickel fluoride or other fluoride salts to the EN bath to achieve higher hardness.

As mentioned above, the Deposition-Floatation model suggests that one way to restrict the auto catalytic reaction to the substrate surface alone will be to see that in case the nickel particles do get detached during the deposition process, they get captured back to the substrate surface. This will prevent them from acting as secondary substrates located elsewhere. Unless this is achieved, on reaching the surface of the electrolyte, the tiny nickel particles, which got attached to the rising hydrogen gas bubbles, will become free when the bubbles burst. This appears to be happening when conventional deposition techniques are employed, causing a random distribution of nickel particles away from the substrate surface, while the auto catalytic reaction is going on. Needless to emphasize, this is a major cause for wastage of nickel as sludge.

In the present set of experiments, the substrates used were in the form of circular discs. Assuming that the gas bubbles rise vertically (with negligible movement in the lateral directions caused by the turbulence in the electrolyte), they should be confined to within the column of electrolyte above the substrate surface to avoid the nickel particles getting scattered randomly. Even though many researchers focused on electroless coating in view of crystallinity, mechanical properties, etc., a specific attention is needed towards the improved of coating efficiency [11, 12]. This will be useful for the industries towards financial profit. Hence, in this work, an advancement in coating methodology by introducing the mechanical deflector is adopted to increase the efficiency of the coating.

\section{EXPERIMENTAL DETAILS}

The proposed work studies on the electroless coating of steel material and its metallurgical efficiency through deflector process. From this investigation, the coatings were subjected to different experimental investigation as planned in the Figure 1a. The investigation implies locating a conical shaped deflector encompassing the substrate 
surface as shown in Figure 1b. The deflector was placed at such a height above the substrate where no gross concentration gradients were allowed to build up within the electrolyte bulk due to lack of convective currents. It is obvious that the geometry and positioning of the deflector should be carefully done for other shapes of the substrate, for achieving satisfactory efficacy of the procedure.

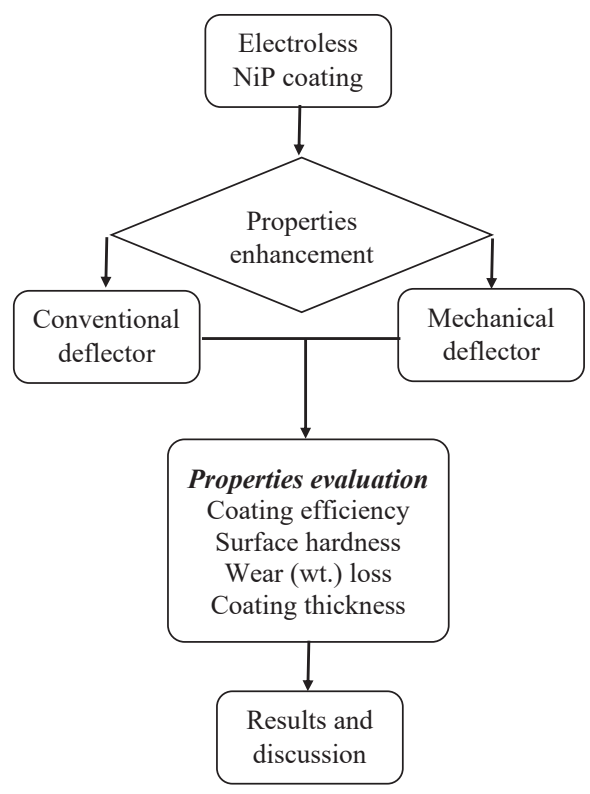

Figure 1a. Workflow chart for the proposed research plan.
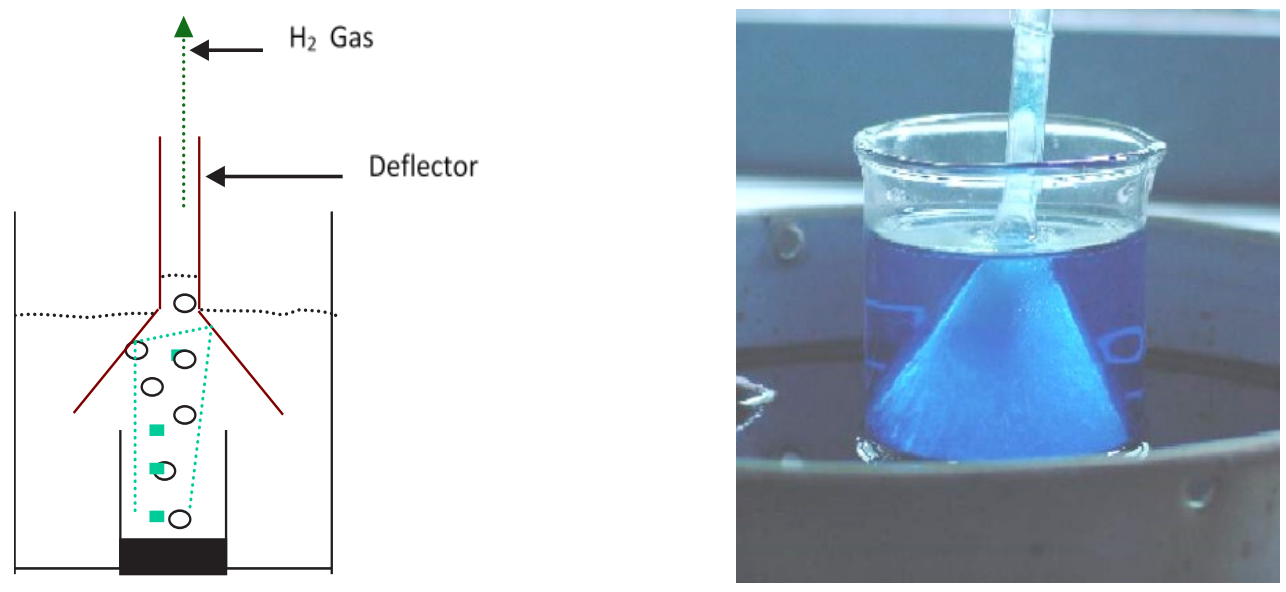

Figure 1b: Conical shaped deflector encompassing the substrate surface for investigation.

The Ni-P coating was deposited to study the hardness and wear behavior after processing. The results inferred were the average of three samples, to ensure the repeatability and reproducibility. The postprocessing operations were performed in two different ways, both conventional and mechanical deflector methods. In both conventional and 
mechanical deflector method of deposition, an optimized process parameter was used. The temperature of the bath was maintained at 700C with the help of PID controller. Nickel chloride $(30 \mathrm{~g} / \mathrm{l})$ and sodium hypophosphate $(40 \mathrm{~g} / \mathrm{l})$ were used as source of nickel and reducing agents. $25 \mathrm{~g} / \mathrm{l}$ sodium citrate, a stabilizer, was used. For the deposits under mechanical deflector, 2.5 Ampere current was employed. Micro hardness of the electroless Ni-P deposits was measured using Shimadzu micro hardness measuring unit employing a diamond indenter. The load applied was 200 gms for $15 \mathrm{sec}$. The VHN value was calculated using the following formula:

$$
\mathrm{VHN}_{200}=\mathrm{P}(1.854) / \mathrm{d}^{2}
$$

As per the ASTM standard B-578-87, the thickness of 30 micrometer was found to be sufficient to avoid substrate effects on hardness measurements.

The equipment consists of a rotating disc with a spherically domed rim, in combination with rotation of the specimen about an intersecting perpendicular axis. The American Society for Testing and Materials (ASTM) standardized Taber tester for organic paint coatings was used for investigation. The wear resistance of electroless Ni$\mathrm{P}$ deposits as estimated by weight loss with wear test time improved on baking for $3 \mathrm{hrs}$ at $9000 \mathrm{~F}$. An increase in the phosphorus of approximately 3-4 wt.\% can change the structure from nanocrystalline to amorphous, and accordingly, the properties and performance of the coating are discussed in detail. The test was interrupted at specific predetermined intervals and weighed to estimate the weight loss. The intervals, designated as wear test time for electroless Ni-P deposits, were 5, 10, 15, 20, 25, and $30 \mathrm{~min}$, and in case of electroless Ni-P/diamond composite coating, 5, 10, 20, 30, and $40 \mathrm{~min}$.

The specific wear rate was estimated using the following equation:

$$
\text { Specific Wear }=\frac{\mathrm{W}}{\text { ALD }}\left(\mathrm{kg} \cdot \mathrm{N}^{-1} \cdot \mathrm{m}^{-3}\right)
$$

Where

$\mathrm{W}$ is the weight loss of the specimen in $\mathrm{kg}$.

$\mathrm{A}$ is the area of the specimen surface subjected of wear in $\mathrm{m}^{2}$.

$\mathrm{L}$ is the vertical force applied on the specimen in Newtons.

$\mathrm{D}$ is the total distance traveled by the specimen during the test in meters.

The above test gives the total wear of the sample, which includes wear of Ni-P as well as the embedded diamond particles. The disc used to test the wear resistance of Ni-P deposits was hardened steel (HRC: 60), and in case of composite coating, the abrasive disc used was an alumina grinding wheel with the specification: $2002531.75 \mathrm{GC} 100$ L5 VG.

\section{RESULTS AND DISCUSSIONS}

The NiP coating processed through conventional and mechanical deflector was analyzed and observed through the electron imaging. Figure 2 represents the SEM image of the coated structure, and it infers that the adherence of the coating is acceptable and good to proceed further. As mentioned earlier, for the purpose of brevity and convenience, the deposits produced by conventional methods will be denoted by $\mathrm{D}_{\mathrm{c}}$ and correspondingly those produced by employing the mechanical deflector by $\mathrm{D}_{\mathrm{F}}$. Figure 3 a presents a comparison of nickel recovery $\left(\mathrm{Ni}_{\mathrm{r}}\right)$ and coating efficiency $(\mathrm{Nic})$ of $\mathrm{DC}_{\mathrm{C}}$ and $\mathrm{DF}_{\mathrm{F}}$. 


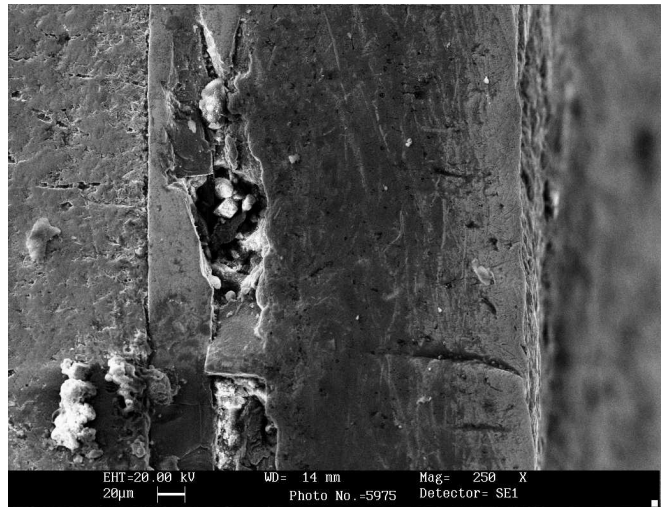

(a) Conventional deflector

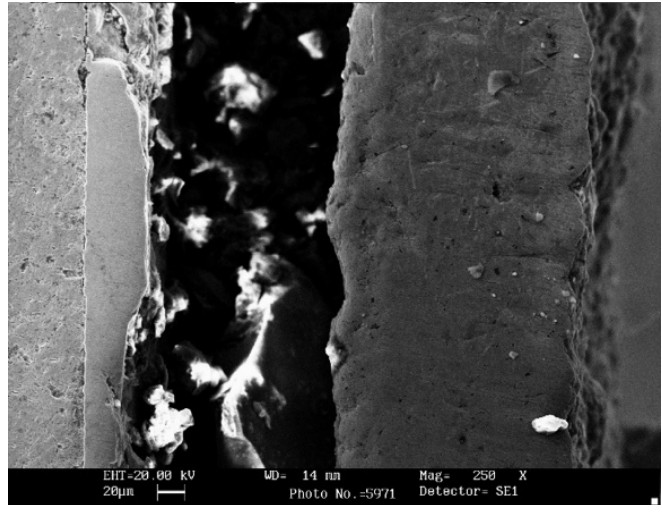

(b) Mechanical deflector

Figure 2. Electron image of the coating made with (a) conventional and (b) mechanical deflector process.

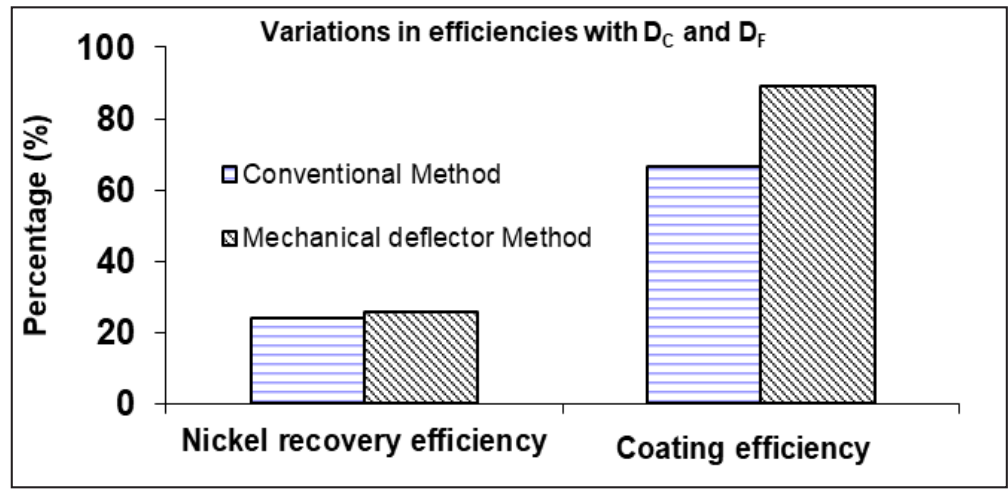

Figure 3a. Variations in efficiencies with $\mathrm{D}_{\mathrm{C}}$ and $\mathrm{D}_{\mathrm{F}}$.

It has been observed that nickel recovery efficiency has not been affected by the presence of mechanical deflector. The result was not unexpected since the nickel recovery can possibly be affected by factors having the capability to influence the chemistry of the autocatalytic reaction. Obviously, the presence of the mechanical deflector did not have any effect. However, a significant increase in the coating efficiency has been observed when $\mathrm{DF}_{\mathrm{F}}$ was considered. It appears that there was an improvement to an extent of about $20 \%$ in the coating efficiency.

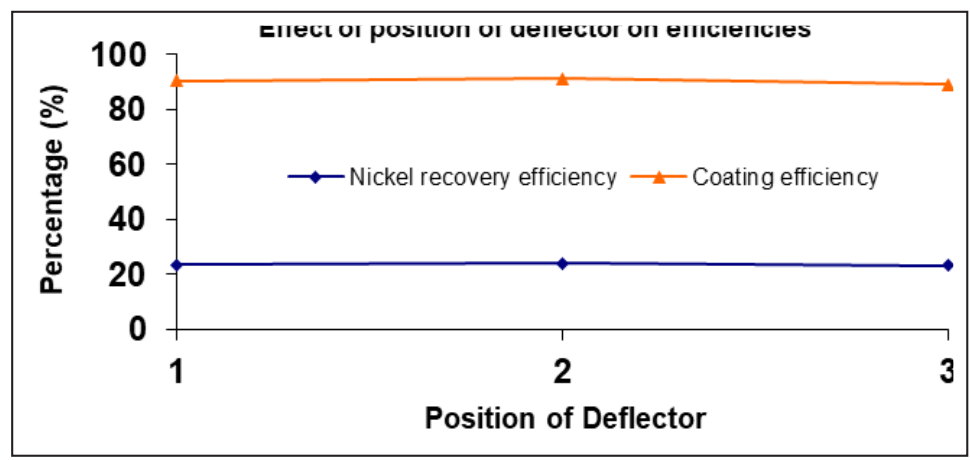

Figure 3b. Effect of position of deflector on efficiencies. 
To check whether the location of the deflector above the substrate surface has any influence, a mechanical deflector was placed at different heights above the substrate, and the experiments were repeated under otherwise identical conditions. The results are presented in figure $3 \mathrm{~b}$. It is seen that both $\mathrm{Ni}_{\mathrm{R}}$ and $\mathrm{NiC}$ were not affected significantly by the position of the deflector. It is probable that these results were specific to the given set of experimental conditions and sample geometry. For complicated specimen geometries, the design of the mechanical deflector might not be as simple as in the present case.

\subsection{Hardness of Electroless Ni-P Deposits}

The mechanical properties, including hardness, were sensitive to heat treatment temperature. In the as-coated condition, the structure of the deposit consisted of a mixture of amorphous and microcrystalline nickel. However, after the heat treatment, conversion to a structure consisting of crystalline FCC nickel and tetragonal $\mathrm{Ni}_{3} \mathrm{P}$ occurs. The conversion appears to be through the nucleation/growth mechanism, causing changes in the hardness of both $\mathrm{D}_{\mathrm{C}}$ and $\mathrm{D}_{\mathrm{F}}$ as shown in figure 4.

The hardness of the deposit increases from about $460 \mathrm{HV}$ to a maximum of about $950 \mathrm{HV}$, apparently due to the precipitation of hard $\mathrm{Ni}_{3} \mathrm{P}$ particles dispersed in a microcrystalline nickel matrix. Above $350^{\circ} \mathrm{C}$, recrystallization/grain growth mechanisms apparently cause reduction in micro hardness levels. Compared to the hardness of deposits produced by conventional method, there was a very slight improvement in the hardness of $\mathrm{D}_{\mathrm{F}}$ both in the as coated and in the heat-treated conditions. Probably, a slight relative reduction in micro-porosity in $\mathrm{D}_{\mathrm{F}}$ could be the reason.

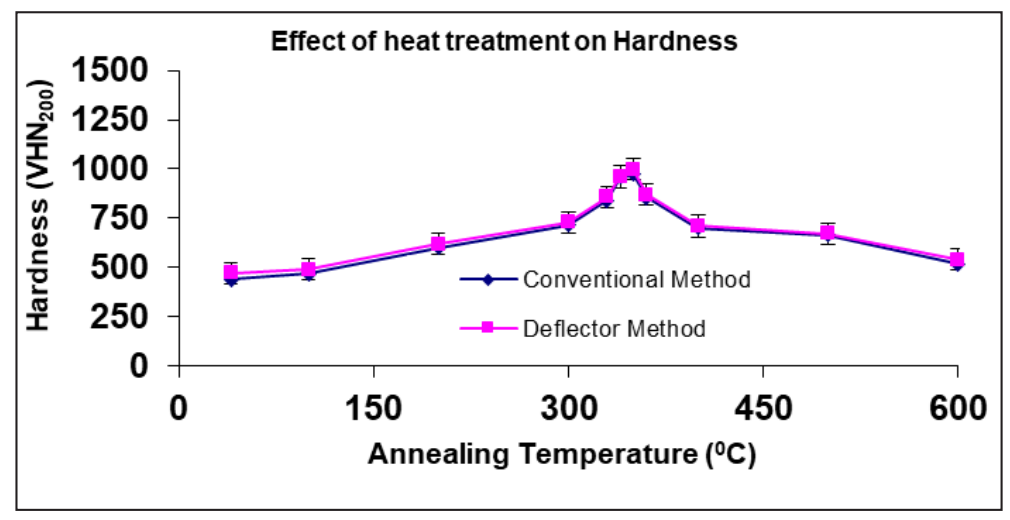

Figure 4. Variation in microhardness of Electroless Ni-P deposits with annealing temperatures (Deposits produced by both DC and DF).

\subsection{Wear Characteristics of Electroless Ni-P Deposits}

The results of the experiments have been carried out for estimating the weight loss of $\mathrm{D}_{\mathrm{C}}$ and $\mathrm{D}_{\mathrm{F}}$ on wear test as shown in figure 5 and figure 6, respectively. In both cases, the weight loss was higher in the as-deposited condition. The wear resistance improves steadily on increasing the heat treatment temperature. It is clear that the hardness is not the only factor that plays a role, although, in the initial stages, it might be the major contributing factor. However, the wear resistance steadily increases even after $350^{\circ} \mathrm{C}$, when, as noted in the previous section, the hardness starts to decrease due to recrystallisation/growth. 


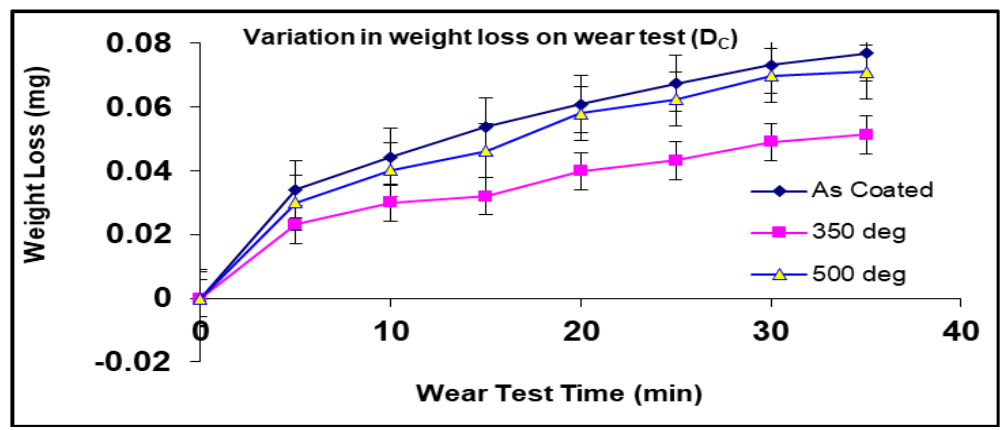

Figure 5. Variation in weight loss of deposits produced by conventional method on wear test.

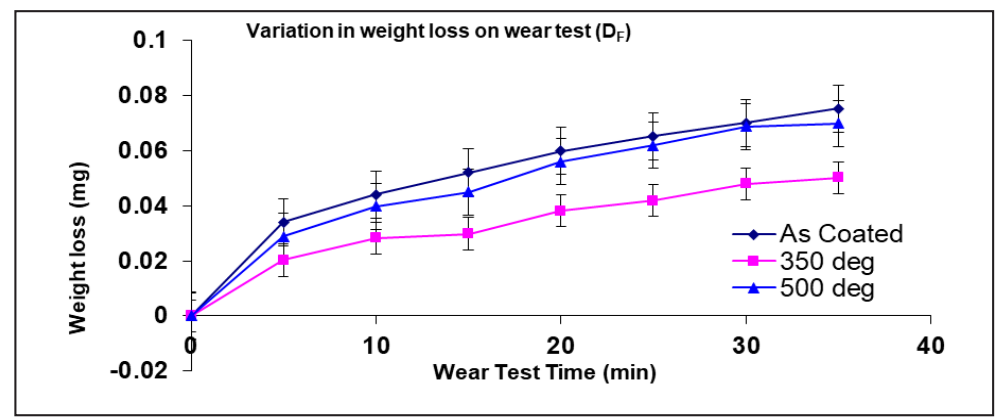

Figure 6. Variation in weight loss of deposits produced by mechanical deflector method on wear test.

Apparently, the appearance of the hard $\mathrm{Ni}_{3} \mathrm{P}$ precipitates in the matrix in steadily increasing proportions helps improve the wear resistance even after the reduction in hardness levels. Results of a comparative study made on the wear characteristics of $\mathrm{D}_{\mathrm{C}}$ and $\mathrm{D}_{\mathrm{F}}$ are presented in figure 7 to figure 9 . It is clear that there was a slight, but nevertheless noticeable improvement in the wear resistance of $\mathrm{D}_{\mathrm{F}}$, in the as-coated, as well as in the heat-treated condition. It was found to be unlikely that this consistent improvement in wear performance of $\mathrm{D}_{\mathrm{F}}$ is due to either higher hardness caused by changes in the mechanism of precipitation, or by the presence of larger quantities of precipitates themselves. This conclusion has been based on the fact that the chemistry of the autocatalytic reaction was identical in both cases. Consequently, it has been concluded that the probable reason was found to be the relatively low micro-porosity levels in the $\mathrm{D}_{\mathrm{F}}$.

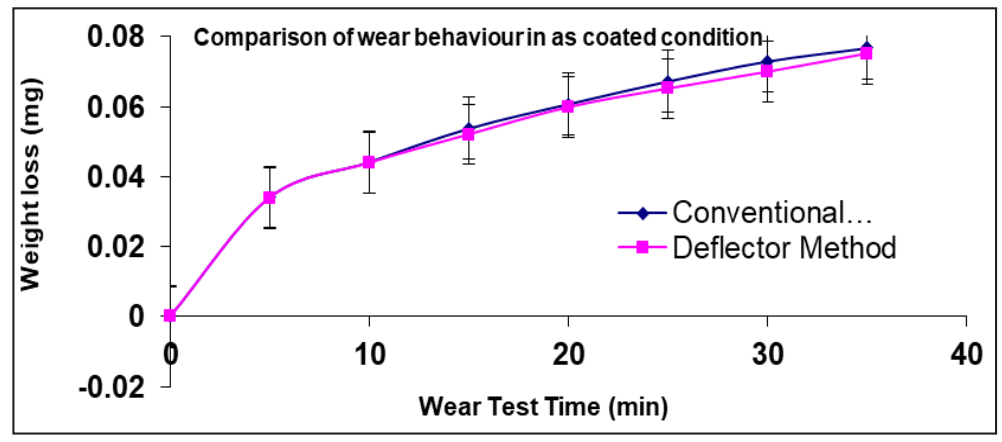

Figure 7. Comparison of wear behavior between conventional and mechanical deflector methods (as-coated condition). 


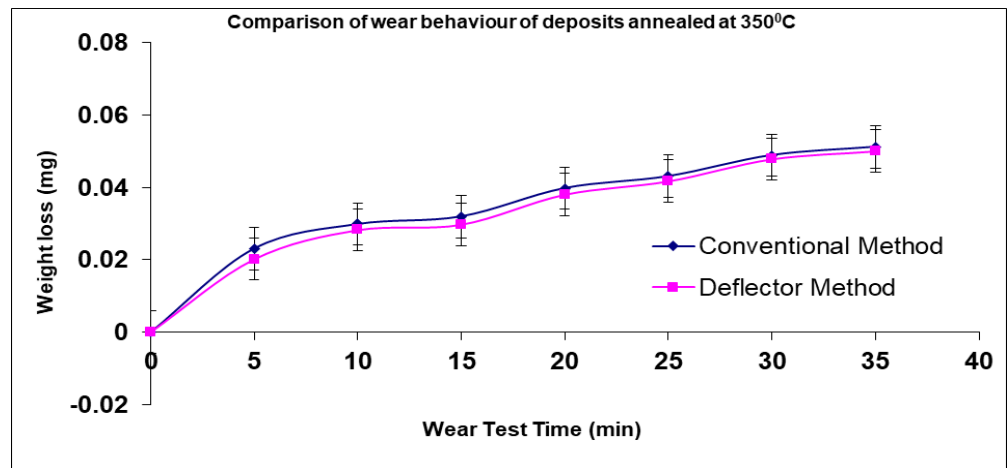

Figure 8. Comparison of wear behavior between conventional and mechanical deflector methods (annealed at 3500C).

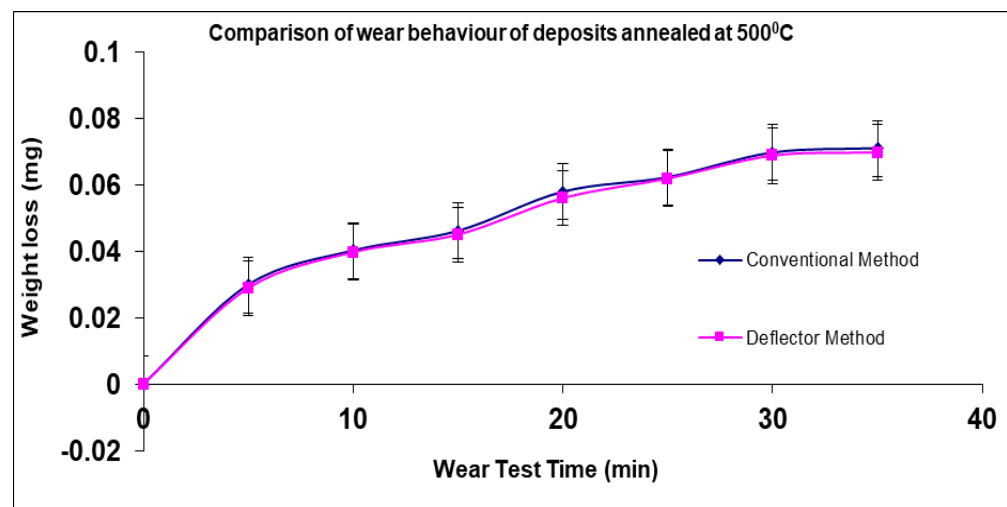

Figure 9. Comparison of wear behavior between conventional and mechanical deflector methods (Annealed at 5000C).

\section{CONCLUSION}

Based on the present investigation, the following broad conclusions could be drawn. The hardness of EN coating produced by the magnetic method and the deflector method is marginally superior to that of deposits produced by conventional methods. On heat treatment, the hardness of the deposits increases, with peak hardness achieved around $350^{\circ} \mathrm{C}$, coinciding with the onset of precipitation of $\mathrm{Ni}_{3} \mathrm{P}$ in the matrix, in all the cases. However, relatively higher hardness was observed in case $\mathrm{D}_{\mathrm{M}}$ and $\mathrm{D}_{\mathrm{F}}$ persist throughout the range of temperatures employed for heat treatment. Wear test clearly indicated superior wear resistance in the case of $\mathrm{D}_{\mathrm{M}}$. The wear resistance of $\mathrm{D}_{\mathrm{F}}$ and $\mathrm{D}_{\mathrm{C}}$ did not show any significant difference. Onset of precipitation of $\mathrm{Ni}_{3} \mathrm{P}$ was relatively sluggish in case of $\mathrm{D}_{\mathrm{M}}$. The magnetic field influences the microstrain and crystallite size of the deposits produced. The values suggest the presence of lower microstrain and higher crystallite size in the case of $\mathrm{D}_{\mathrm{M}}$. This difference persists throughout the range of heat treatment employed. 


\section{REFERENCES}

Andréa Moura Bernardes, Marco Antônio Siqueira Rodrigues, Jane Zoppas Ferreira, Electrodialysis and Water Reuse: Novel Approaches, Springer Science \& Business Media, NY, 2013

E.V. Krylov, E.G. Nazarov, Electric field dependence of the ion mobility, International Journal of Mass Spectrometry 285 (2009) 149-156

J.L. Luque García, M.D. Luque de Castro, Acceleration and Automation of Solid Sample Treatment, Elsevier Science Inc., Netherland, 2002.

C. D. M. Campos, A. Flacker, S. A. Moshkalev, E. G. O. Nobrega, Comparative analysis of thin Ni and CoNiMnP magnetic film, Thin Solid Films, 520(15) (2012) 4871 - 4874.

Yu. E. Sknar, O. O. Savchuk, I. V. Sknar, Characteristics of electrodeposition of Ni and Ni-P alloys from methanesulfonate electrolytes, Applied Surface Science, 423 (2017) 340-348

Jia-Hong Ke, George A. Young, Julie D.Tucker, Ab initio study of phosphorus effect on vacancy-mediated process in nickel alloys - An insight into Ni2Cr ordering, Acta Materialia, 172 (2019) 30-43

Pillai, A.M., Rajendra, A. \& Sharma, A.K. Electrodeposited nickel-phosphorous (Ni-P) alloy coating: an indepth study of its preparation, properties, and structural transitions. J Coat Technol Res 9, 785-797 (2012).

B. Bahadormanesh and M. Ghorbani. "Electrodeposition of $\mathrm{Zn}-\mathrm{Ni}-\mathrm{P}$ compositionally modulated multilayer coatings: An attempt to deposit Ni-P and Zn-Ni alloys from a single bath". In: Electrochemistry Communications, 81 (2017), pp. 93-96

A. Hadipour, S. M. Monirvaghefi and M. E. Bahrololoom, Electroless deposition of graded Ni-P coatings, Surface Engineering, 31(6) (2015) 399 - 405.

Martin Buchtík, Michaela Krystýnová, Jǐrí Másilko and Jaromír Wasserbauer, The Effect of Heat Treatment on Properties of Ni-P Coatings Deposited on a AZ91 Magnesium Alloy, Coatings 2019, 9, 461 469

Güler, O., Alver, Ü. and Varol, T., 2020. Fabrication and characterization of novel layered materials produced by electroless plating and hot pressing. Journal of Alloys and Compounds, 835, p.155278.

Güler, O., Varol, T., Alver, Ü. and Biyik, S., 2021. The wear and arc erosion behavior of novel copper based functionally graded electrical contact materials fabricated by hot pressing assisted electroless plating. Advanced Powder Technology. 